\title{
Classical and recent advances in the treatment of inflammatory bowel diseases
}

\author{
H. Sales-Campos ${ }^{1}$, P.J. Basso ${ }^{2}$, V.B.F. Alves ${ }^{1}$, M.T.C. Fonseca ${ }^{2}$, G. Bonfá2 ${ }^{2}$ \\ V. Nardini ${ }^{1}$ and C.R.B. Cardoso ${ }^{1}$ \\ ${ }^{1}$ Departamento de Análises Clínicas, Toxicológicas e Bromatológicas, Faculdade de Ciências Farmacêuticas de Ribeirão Preto, \\ Universidade de São Paulo, Ribeirão Preto, SP, Brasil \\ ${ }^{2}$ Departamento de Imunologia e Bioquímica, Faculdade de Medicina de Ribeirão Preto, Universidade de São Paulo, \\ Ribeirão Preto, SP, Brasil
}

\begin{abstract}
Crohn's disease (CD) and ulcerative colitis (UC) are intestinal disorders that comprise the inflammatory bowel diseases (IBD). These disorders have a significant effect on the quality of life of affected patients and the increasing number of IBD cases worldwide is a growing concern. Because of the overall burden of IBD and its multifactorial etiology, efforts have been made to improve the medical management of these inflammatory conditions. The classical therapeutic strategies aim to control the exacerbated host immune response with aminosalicylates, antibiotics, corticosteroids, thiopurines, methotrexate and antitumor necrosis factor (TNF) biological agents. Although successful in the treatment of several CD or UC conditions, these drugs have limited effectiveness, and variable responses may culminate in unpredictable outcomes. The ideal therapy should reduce inflammation without inducing immunosuppression, and remains a challenge to health care personnel. Recently, a number of additional approaches to IBD therapy, such as new target molecules for biological agents and cellular therapy, have shown promising results. A deeper understanding of IBD pathogenesis and the availability of novel therapies are needed to improve therapeutic success. This review describes the overall key features of therapies currently employed in clinical practice as well as novel and future alternative IBD treatment methods.
\end{abstract}

Key words: Inflammatory bowel disease; Crohn's disease; Ulcerative colitis; Treatment; Immune modulation; Cellular therapy

\section{Introduction}

Intestinal infirmities affect people in every region of the world and are responsible for various physical, nutritional and immunological disabilities. The chronic inflammation resulting from ulcerative colitis (UC) and Crohn's disease (CD), known as inflammatory bowel diseases (IBD), leads to a wide range of signs and symptoms such as diarrhea, abscesses, fistulas, abdominal pain and stenosis that have a significant effect on the quality of life of affected patients (1).

The prevalence and incidence of UC and CD are highest in Europe and North America $(2,3)$, but an increase in IBD cases has been observed recently in Asia, especially in China (4). Data regarding IBD incidence and prevalence in developing countries are scarce, but the available studies show a trend towards increasing rates for UC followed by CD (5).

The global burden of IBD has spurred efforts to improve the effectiveness of medical therapy. These efforts have focused on the reduction of inflammation, induction of longterm remission periods, improvement of quality of life of patients, and development of novel therapeutic approaches. In this review, we describe the classical therapies and most recent advances in the treatment of IBD, whose etiology seems to be dependent on the multifaceted interaction among immune, environmental, microbial and genetic factors.

\section{IBD treatment}

Traditionally, the goals of pharmacological or biological treatment for both $\mathrm{CD}$ and $\mathrm{UC}$ have been reduction of inflammatory process during relapses and extending the period in which the patient is maintained in remission of clinical symptoms. Hence, IBD treatment depends on the balance between efficacy and secondary side effects of the drugs used, in addition to the patient's response to prior therapy. The choice of therapy should also be based on the frequency of disease relapse, the extent and severity of disease, and the presence of extra-intestinal manifestations, which indicate serious complications of IBD. Additional

Correspondence: C.R.B. Cardoso: <cristina@fcfrp.usp.br>.

Received March 1, 2014. Accepted September 25, 2014. First published online November 28, 2014. 
factors influence the therapeutic management of the intestinal inflammation, such as the lesion site, activity of the disease and the overall clinical status of each individual patient (6). Furthermore, though UC and CD share similar clinical features, they may be distinguished by disease location and characteristics of inflammation. The main difference is that, in CD, inflammation can be observed throughout the entire gastrointestinal tract, compromising the entire bowel wall, while in UC the inflammation is restricted to the epithelial lining and limited to the large intestine (1). The differences in the clinical features of these two entities, in addition to differences in environmental influences and the genetic makeup and immune status of each patient, explain why medical interventions should be individualized and constantly monitored by physicians, in order to achieve the best outcomes for UC or CD.

IBD treatment may also comprise two different therapeutic approaches known as "step-up" or "top-down" strategies. The first refers to the classical method in which the intensity of treatment increases along with the severity of disease. On the other hand, "top down" strategies include an early onset of intensive treatment such as biological therapies in order to avoid the occurrence of future complications (6). However, the choice of one of these different approaches by the physician depends on the patient's responsiveness to prior therapies, clinical condition and the diagnosis. The treatment choices for UC or CD differ because they are unique entities with different pathophysiological aspects. Furthermore, current therapies are not totally curative, and subjects may be refractory or unresponsive, and treatments that successfully control gastrointestinal inflammation without undesired side effects are still missing from clinical practice. Thus, an ideal therapy must comprise an immune modulator that efficiently controls inflammation without leading to exacerbated immunosuppression. It should also cause minimal adverse effects with reduced or absent bacterial translocation, infection-related complications or progression to cancer. Due to the complexity of IBD pathogenesis, the reestablishment of the immune balance in the intestine, or a treatment that efficiently combines immune suppressors, biological therapy, and a modulator of intestinal microbiota, would also be of major importance.

Pharmacological therapies for IBD usually include wellestablished drugs (Figure 1) recognized as conventional therapies. These comprise five distinct pharmacological classes: aminosalicylates, antibiotics, corticosteroids, thiopurines, and folic acid antagonists such as methotrexate, as reviewed by Taylor et al. (7). Conventional and novel therapies for CD or UC are listed in Table 1.

\section{Aminosalicylates}

Aminosalicylates (ASA) are a group of drugs containing the active ingredient 5-aminosalicylic acid (5-ASA).

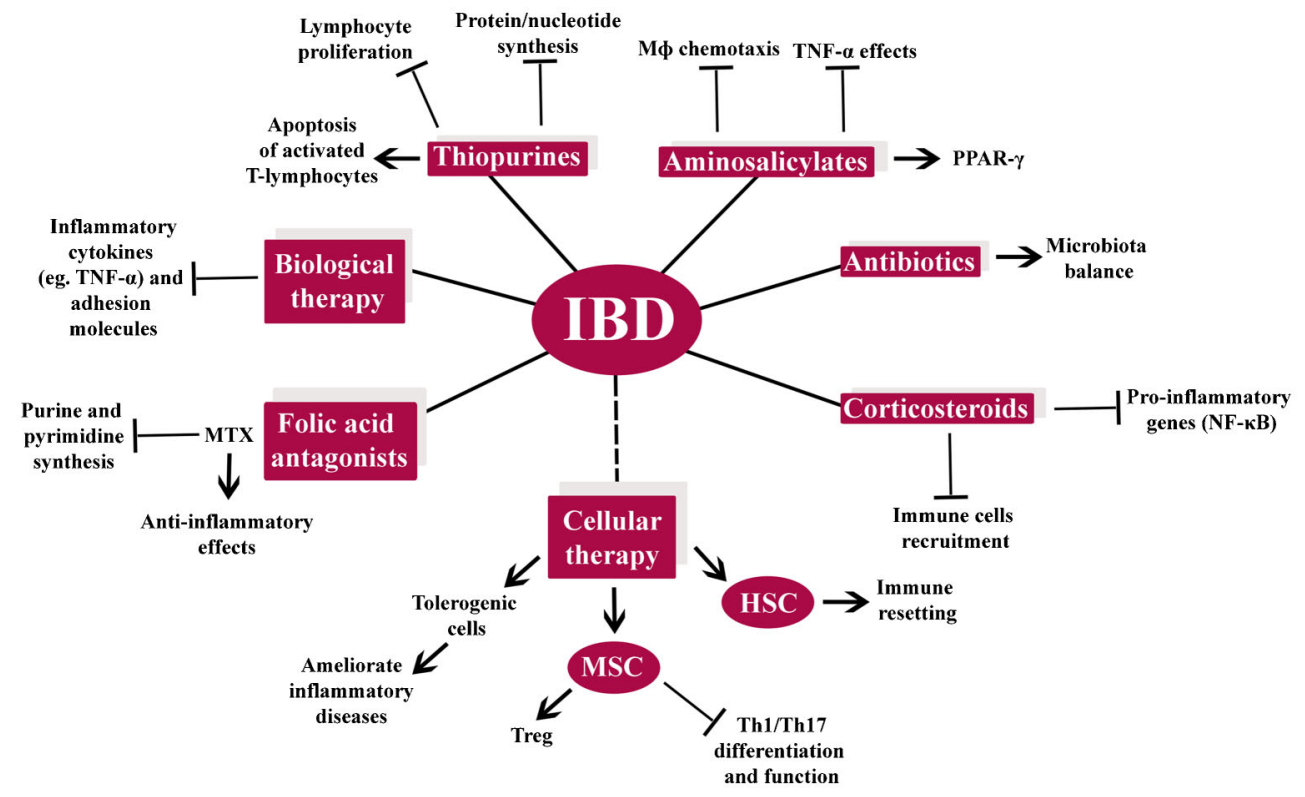

Figure 1. Current and emerging therapies for inflammatory bowel disease (IBD). The classical treatments for IBD include aminosalicylates, antibiotics, corticosteroids, thiopurines, folic acid antagonists (methotrexate) and anti-TNF- $\alpha$ biological agents. All these drugs have different targets that contribute to the regulation of the exacerbated immune responses in Crohn's disease or ulcerative colitis patients. Continuous lines indicate drugs currently used in IBD treatment while the dashed line is related to the emerging cellular therapy. Arrows: induction or stimulatory events. Blocked arrows: inhibitory actions of the indicated therapy. HSC:

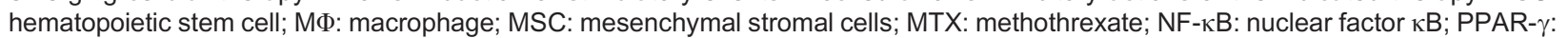
peroxisome proliferator-activated receptor $\gamma$; Th: T helper cell; Treg: T regulatory cell; TNF- $\alpha$ : tumor necrosis factor $\alpha$. 
Table 1. Summary of the main classical and novel approaches for IBD treatment.

\begin{tabular}{ll}
\hline Ulcerative colitis & Crohn's disease \\
\hline Aminosalicylates & Folic acid antagonists \\
Modulators of intestinal microbiota & Modulators of intestinal microbiota \\
Corticosteroids & Corticosteroids \\
Thiopurines & Thiopurines \\
JAK inhibitors & anti-TNF antibodies \\
& anti-IL-12 antibodies \\
& anti- $\alpha 4$ leukocytes integrin \\
& HSCT \\
& MSC \\
\hline
\end{tabular}

JAK: janus kinase; TNF: tumor necrosis factor; IL-12: interleukin 12; HSCT: hematopoietic stem cell transplantation; MSC: mesenchymal stromal cells.

Beneficial effects of ASA are related to the inhibition of macrophage chemotaxis or to an increase in intestinal epithelial cell proliferation due to the inhibition of tumor necrosis factor (TNF)- $\alpha$ effects (Figure 1), and the downstream mitogen-activated protein (MAP) kinase and nuclear factor (NF)- $\mathrm{kB}$ signaling pathways (8). ASA also exerts its effects in IBD through the activation of peroxisome proliferator activated receptor $\gamma$ (PPAR $\gamma$ ) (9). Of note, PPAR $\gamma$ is typically expressed in epithelial and immune cells in the colonic mucosa and is important in the regulation of IBD, especially because of its ability to antagonize inflammatory molecules such as nuclear factor kappa B (NF-kB), signal transducers and activators of transcription (STAT) and activator protein (AP-1) (10).

These compounds are used as the first-line drugs to treat $\mathrm{UC}$ for both induction and maintenance of remission, and are safe and tolerable for most patients. Their use in patients with $C D$ remains controversial. Despite their limited use in $C D$, a multicenter study in patients with mild to moderate active disease reported that treatment with $4.5 \mathrm{~g}$ /day mesalazine led to remission and a decrease in Crohn's Disease Activity Index comparable to $9 \mathrm{mg} /$ day budesonide (11).

The most frequently prescribed aminosalicylates used to treat IBD are mesalazine, sulfasalazine, olsalazine, and balsalazide. Although the therapy is widely used, especially to treat UC patients, it can present some adverse effects. Side effects differ among clinical trials and patients, and sometimes are similar to those reported by placebo-treated subjects. Those most frequently described are diarrhea, nausea, vomiting, headache, abdominal pain, fatigue, weaknesses, hepatic abnormalities, arthralgia and myalgia (12).

In an attempt to reduce the number of pills required daily for 5-ASA treatment, clinical trials have focused on the administration of a single daily dose rather than twice- or multiple-dose regimens. Any resulting improved adherence to 5-ASA therapy would be expected to reduce risk of disease relapse. In this context, a survey showed that oncedaily dosing is also preferred by UC patients (13). Although mesalazine is the most used ASA to treat IBD, some patients may be poorly responsive to this therapy. However, a study conducted in Spain demonstrated the ability of sulfasalazine to successfully treat patients refractory to ASA under such conditions (14).

Thus, although aminosalicylates are the first choice for treatment of UC, poorly responsive patients or the presence of some significant side effects constitute an important barrier to completely successful therapy. The use of these compounds to treat $\mathrm{CD}$ is controversial, and additional basic research and further clinical trials are needed to determine their real therapeutic role in those patients.

\section{Modulators of intestinal microbiota: antibiotics and probiotics}

It is well established that intestinal bacteria counts are higher in IBD patients than in healthy individuals and this increased microbial load is positively related to augmented disease severity. In CD, this imbalance could be a result of a prevalence of harmful bacteria such as Escherichia or Shigella over protective species such as Faecalibacterium (15).

Considering the predominance of harmful bacteria and their relationship to infectious complications caused by immunosuppressive drugs and downregulation of mucosal immunity, the use of antibiotics for IBD treatment cannot be underestimated. In this context, broad-spectrum antibiotics are used by clinicians as a primary or adjuvant treatment. As a primary therapy, metronidazole $(20 \mathrm{mg} / \mathrm{kg})$ was found to induce a decrease in the Crohn's Disease Activity Index (16). A different study found that metronidazole was not effective for primary reduction of CD activity (17), but that it was well tolerated, produced minimal adverse effects, and reduced some secondary chronic manifestations such as perianal pain. A multicenter trial in Sweden, also using metronidazole, showed similar effects for sulfasalazine as a primary treatment for CD (18). Furthermore, metronidazole or ciprofloxacin have been used as an adjuvant treatment of bacterial overgrowth in IBD intended to decrease bacterial translocation (19), thus reducing disease severity. 
Patients given ciprofloxacin (500 mg twice a day) for treatment of perianal fistulizing $C D$ had $30 \%$ fistula remission after 10 weeks of therapy compared with 0 and $12.5 \%$ of fistula remission achieved with metronidazole or placebo, respectively (20). It is important to note that significant differences among the groups were not observed in that study, probably due to the small sample size. Treatment of active CD with $800 \mathrm{mg}$ rifaximin twice daily resulted in improved clinical remission compared with patients who received only placebo (21). Treatment with ornidazole (1 g/day) (22) was more effective than placebo for reducing the rate of $C D$ recurrence after surgery. Another study reported a greater reduction of CD recurrence in patients treated with metronidazole and azathioprine compared with those who received metronidazole plus placebo (23). In general, antibiotics constitute an important supplementary therapy to reduce intestinal bacterial load, risk of relapse, progression, and disease severity (Figure 1). However, antimicrobial therapy can lead to dysbiosis, which could result in the expansion of detrimental bacteria populations and disease worsening. Furthermore, since IBD presents a multifactorial etiology, exclusive use of antibiotic therapy may not be sufficient to control the exacerbated intestinal inflammation.

Because antibiotics alone are not able to efficiently restore the balance between detrimental and beneficial microorganisms in the intestine, alternative therapies are needed to achieve this control. Thus, another possibility to restore intestinal homeostasis is through probiotics. Beneficial bacteria may change gene expression patterns, modulate host immune response, and modify blood and tissue metabolic profiles (24). The potential effect of probiotics in the treatment of IBD is not totally clear, but some studies have shown that VSL\#3, a mixture of Lactobacillus casei, L. plantarum, L. acidophilus, L. delbrueckii subsp. bulgaricus, Bifidobacterium longum, B. breve, B. infantis and Streptococcus salivarius subsp. thermophiles, was able to induce remission in patients with mild-to-moderately active UC (25). Although it is still uncertain whether dysbiosis is a cause or consequence of IBD, all of these studies indicate that manipulation of microbiota may be an important therapeutic strategy to protect from or to treat the intestinal inflammation.

\section{Corticosteroids}

To treat acute exacerbations of IBD, corticosteroids constitute one of the best therapeutic options since they act by downregulating the transcription of proinflammatory genes (e.g., NF-kB) involved in cytokine production. Corticosteroids also inhibit the recruitment of immune cells and the expression of adhesion molecules in inflamed tissue (Figure 1). However, if corticosteroids are used daily and long-term, even at low doses, there is an increase in the occurrence of adverse effects such as osteoporosis, metabolic syndrome, cardiovascular disease, infections, osteonecrosis, and cataracts (26).
In the early 1960's, a study conducted in outpatients with UC treated with three different prednisone doses (20, 40, and $60 \mathrm{mg} /$ day) showed that this corticosteroid was more effective at $40 \mathrm{mg}$ than at $20 \mathrm{mg}$. Moreover, when patients were treated with $60 \mathrm{mg}$ daily, they had more adverse effects, and the increased dose was not more effective than $40 \mathrm{mg}$ (27). As an alternative to the side effects observed during prednisone therapy, prednisolone metasulfobenoate was associated with less pronounced side effects and had an efficacy similar to prednisolone in a double-blind, randomized, controlled trial (28).

Budesonide is also effective in inducing remission in UC, as observed in a study of 410 patients given an oral dose of $9 \mathrm{mg}$ once daily for 8 weeks (29). Furthermore, when an extended time-release formulation was used to improve budesonide effects throughout the colon, UC remission was also observed in patients with active mild-tomoderate disease (30).

Because systemic steroid therapy may present various side effects, other treatment approaches with reduced systemic activity are necessary. However, topical application is an alternative for corticosteroid therapy. The effectiveness of combined topical corticosteroid and 5-ASA therapies was shown in a multicenter randomized trial. That study demonstrated the superiority of combined therapy when compared with monotherapy for improvement of clinical, histological, and endoscopic aspects of UC patients with proctitis (31). Another study compared the effectiveness of budesonide vs mesalazine enemas in patients with active left-sided ulcerative colitis. Although mesalazine was slightly more effective, corticosteroid therapy also improved endoscopic and histological outcomes and disease remission rates (32). In addition, combined treatment with immunosuppressive drugs such as 6-mercaptopurine and corticosteroids (prednisone) increased the remission period and decreased the use of steroids in children with CD (33).

Although corticosteroid therapy is effective in the treatment of IBD, patients may present variable degrees of glucocorticoid sensitivity, showing no response or even steroid therapy-related side effects. In order to determine whether inflammatory cytokines were related to corticosteroid failure, a study of 79 pediatric UC patients was performed. Of all the cytokines studied, only IL-6 had a positive correlation with increased corticosteroid unresponsiveness. Moreover, although IL-6 predicted treatment failure, it seemed to be due to the disease activity and not because of any interference in the corticosteroid pathway (34). Furthermore, some genetic polymorphisms might also be related to a nonresponsive condition in IBD patients. An increased frequency of mutated $B c / l$ genotype in the glucocorticoid receptor gene NR3C1 (nuclear receptor subfamily 3 , group $C$, member 1 ) was described in responsive IBD patients compared with nonresponders but a mutation in the NALP1 gene was significantly more frequent in resistant patients (35). 
In summary, corticosteroid therapy has long been used to treat IBD and is one of the best choices to treat acute exacerbation. However, the presentation of adverse effects, especially with systemic administration, coupled with the unresponsiveness observed in some patients, presents an important barrier to their continuous use. Therefore, an attempt to reduce the occurrence of adverse effects, such as the use of topical application, seems to be a promising approach. Furthermore, in order to improve therapeutic efficacy, genetic screening could be used to discriminate between responsive and unresponsive patients and establish pharmacogenetic approaches for corticosteroid administration.

\section{Thiopurines}

The thiopurine immunosuppressants azathioprine (AZA) and 6-mercaptopurine (6MP) are fundamental drugs in IBD treatment, and have been effectively used for more than 40 years for induction and maintenance of remission. Such compounds are indicated in patients with dependence on corticosteroids (36) and as a therapy to reduce recurrence after surgery in CD patients (37).

Though the mechanisms of action of thiopurines in IBD are not completely understood, their effects have been associated with both an inhibition of nucleotide or protein synthesis and lymphocyte proliferation (Figure 1). Furthermore, thiopurines may be able to induce apoptosis of activated T-lymphocytes. This programed cell death may be associated with a reduction in inflammation due to a block in the expression of molecules such as TNF-related apoptosis-inducing ligand (TRAIL), tumor necrosis factor receptor superfamily, member 7 (TNFRS7) and $\alpha 4$-integrin, through a common metabolite of both AZA and 6MP known as 6-thioguanine nucleotide (6-TGN) (38).

Regarding the timing of initiation of therapy with thiopurines, evidence from different studies suggests that when these compounds are used early in disease the clinical course can be modified. When the influence of the timing of treatment onset with thiopurines was evaluated in children, those who received early thiopurine therapy (within 3 months of diagnosis) had lower rates of corticosteroid introduction after the first year of treatment than those who received late therapy (within 3-12 months of diagnosis). Furthermore, the group that initiated earlier treatment had fewer hospitalization episodes after 2 years of treatment (39). Moreover, in a prospective study of 238 patients with CD and 156 with UC, treatment with azathioprine for 38 months decreased the rate of hospitalization and surgery compared with the period before the start of azathioprine therapy. Azathioprine also had a sparing effect on glucocorticoid use by patients receiving early treatment (40).

It is important to mention that in patients refractory to azathioprine treatment, especially due to the occurrence of undesirable effects in the liver or joints, arthralgia, and myalgia, the use of 6MP could be considered. It is well tolerated by half of the patients who are intolerant to azathioprine (41).
Even though the exact mechanisms of action of thiopurines in IBD are not completely known, their role as immunosuppressants is of great importance to restore the immune balance in the intestine and thus to justify their use in the induction and maintenance of disease remission.

\section{Folic acid antagonists}

Methotrexate (MTX) is the major folic acid antagonist used to threat autoimmune diseases. MTX may be prescribed for patients refractory or intolerant to thiopurine therapy, and is generally preferred for induction and maintenance of remission in CD. However, this drug has low efficacy regarding long-term effects (42). Furthermore, its use in UC remains controversial, as treatment with this drug in a double-blind, randomized multicenter trial for UC was not found to be effective (43). However, Cummings et al. (44) demonstrated that MTX might have therapeutic effectiveness in UC, when used at higher doses than in the previous study (43). Additionally, the effectiveness of MTX to treat IBD may be related to the route of drug administration, and MTX may be better tolerated by patients when administered subcutaneously rather than intramuscularly (45).

The mechanism of action of MTX is associated with its ability to inhibit some enzymes related to the folate pathway (Figure 1) and involved in purine and pyrimidine synthesis. This inhibition leads to an increase in the extracellular levels of adenosine that is related to the anti-inflammatory properties of MTX (46). Furthermore, although hepatotoxicity is infrequent among IBD patients, this undesirable effect may occur under some specific conditions (47).

Overall, these findings point to the ability of MTX to induce and maintain $C D$ remission. However, despite the frequent use of MTX in patients intolerant or refractory to thiopurines, its long-term low efficacy, coupled with the need for increased doses in some cases, may reduce the potential for wide use of this drug in clinical practice.

\section{Biological therapy}

As previously reviewed (1), the pathogenesis of IBD involves leukocyte activation with the production of inflammatory mediators that culminate in gut lesions. Consequently, a primary goal of several therapies is to block the immune system activity and thus inhibit proinflammatory cytokines, chemokines and integrins. The administration of anti-inflammatory cytokines and induction of cell death may also contribute to prevention of the activation, proliferation and/or recruitment of $\mathrm{T}$ cells (48). A promising strategy to achieve these goals is the development of biological agents, which are so termed because of their protein origin (e.g., antibodies and cytokines). However, although usually highly efficacious, this therapeutic approach increases the cost of IBD treatment, and clinicians should always consider this condition.

Although many different procedures using biological therapy have shown favorable results, most are still under 
investigation. Thus, we describe anti-TNF therapy in some detail here because it is the biological drug most widely used in clinical protocols for IBD; other strategies will be briefly discussed at the end of this topic.

TNF is a cytokine that plays an important role in the pathogenesis of IBD, as well as in other immunological diseases such as rheumatoid arthritis, ankylosing spondylitis and psoriasis (49). TNF-specific monoclonal antibodies (Figure 1) were developed as a new treatment alternative and should be used in case of unresponsiveness or contraindications to the other treatments discussed above (50). This therapeutic approach is highly effective for the treatment of moderate-to-severe disease, primarily as induction and maintenance therapy in CD (51).

A number of different anti-TNF antibodies are available, such as infliximab, adalimumab, certolizumab pegol, and golimumab. Infliximab is a chimeric mouse-human monoclonal antibody directed specifically to TNF (51). It was developed as a therapeutic agent for immune-mediated diseases, and in IBD it is currently used chiefly in the treatment of CD and occasionally UC. Infliximab also has beneficial effects in the healing of fistulas in CD (52). The mechanism of action of infliximab involves its binding to both soluble and membrane-bound TNF, with subsequent inhibition of the biological activity of this cytokine (50). Infliximab should be administered intravenously, and patients can benefit from a dose of $5 \mathrm{mg} / \mathrm{kg}$ and variable dosing schedules (53). Although usually effective, the loss of response in CD patients treated with biological agents is around $36 \%(54)$, and the undesirable outcome of these therapies may be associated with the synthesis of antiinfliximab (IFX) antibodies by the patient (55). However, a recent study showed that the disease remission rates in patients who have anti-IFX antibodies are equal to the rates seen in those negative for anti-IFX (56). Further studies are needed to understand the reasons for treatment failure and to improve future therapy in those patients. Moreover, infusion reactions typically occur with drug administration (e.g., acute hypersensitivity and delayed-type hypersensitivity reactions) and appear to be more frequent in antiIFX positive patients, who must, therefore, be constantly monitored (56).

Adalimumab is an anti-TNF monoclonal antibody with complete human molecular composition. Patients intolerant to infliximab may use it, since there are no murine sequences in its molecular structure (52). Adalimumab should be administered subcutaneously. Patients with CD who are responsive to adalimumab treatment may achieve deep remission, with improved outcomes and quality of life (57).

Certolizumab pegol and golimumab may also be used for CD patients who are unresponsive to the other anti-TNF therapies, both with good prospects $(58,59)$. Certolizumab pegol is not a complete antibody, but lacks the Fc portion, and is a pharmacokinetically stable, pegylated Fab' humanized monoclonal antibody (60). It is administered by subcutaneous injection. The biological functions performed by the Fc fragments (e.g., complement activation and antibody-dependent cellular cytotoxicity) thus do not appear to be important to the outcome of certolizumab pegol therapy in IBD (60). Golimumab is a human monoclonal antibody and should also be administered subcutaneously. It is effective in reducing the signs and symptoms of IBD, and the clinical response in patients with moderate to severe $\mathrm{UC}$ is associated with serum golimumab concentration (59).

Although biological therapies targeting TNF have shown great efficacy, especially in those cases refractory to conventional treatments, their use might lead to the occurrence of undesirable effects such as the hypersensitivity reactions described above. Therefore, it is important to stress the possibility of the formation of antibodies against anti-TNF agents, infusion reactions (burning sensation, itching, erythema, delayed hypersensitivity-like reactions), infections (especially when combined with immunosuppressive therapy such as corticosteroids), autoimmunity, and to a lesser degree, malignancies such as lymphomas (61).

The impact of anti-TNF antibody treatment in pregnant women and fetuses appears to be relatively low, even with the ability of these antibodies to cross the placenta (after the second trimester of pregnancy) and be present in breast milk (62). On the other hand, these possible interactions should not be underestimated, and more rigorous studies must be performed, since anti-TNF antibodies persist at high concentrations in newborns for up to 6 months (63).

The chronic intestinal inflammation induced by 2,4,6trinitrobenzene sulfonic acid (TNBS) in a mice model of IBD involves production of IL-12 and IFN- $\gamma$ with subsequent participation of T helper (Th)1 cells (64). Therefore, another therapeutic option could be the neutralization of IL-12 during disease development. In fact, short- and long-term treatment with monoclonal anti-IL-12 antibody in experimental colitis has been shown to improve several clinical and histopathological signs of disease (64). These data led to the hypothesis that anti-IL-12 could be a beneficial therapy for patients with CD. Later, it was found that IL-12 shares the structural subunit $\mathrm{p} 40$ with IL-23, which also plays a crucial role in IBD pathogenesis (65). Thus, a human monoclonal antibody directed against the common p40 subunit of IL-12 and IL-23 (ustekinumab) can inhibit the biological activity of Th1 and Th17 pathogenic cells (66). Indeed, patients with moderate to severe CD who were resistant to anti-TNF had promising disease outcomes when treated with ustekinumab, and they had increased remission when this drug was used as principal treatment (67).

Another important biological therapy developed for inflammatory diseases is natalizumab, a recombinant humanized monoclonal antibody directed against $\alpha 4$-integrin from leukocytes (68). The mechanism of action of natalizumab involves the prevention of T-cell migration to inflammatory sites such as the intestine. A recent study in CD patients refractory to conventional therapies showed that natalizumab treatment was safe and led to promising 
results as an alternative therapy of IBD (69).

As most of the available biological therapies are directed at the blockage of only one cytokine, it seems reasonable to believe that the modulation of a common cytokine downstream pathway could represent an attractive therapeutic approach. Thus, therapies directed at modulation of the Janus kinase (JAK) signal transducer pathway, with a number of downstream cytokine receptors including those containing the common gamma chain (interleukins including $2,4,7,9,15$, and 21), may represent a promising treatment (70). In this context, tofacitinib, an orally-administered selective inhibitor of the JAK family, including JAK1 and JAK3, has shown encouraging results, especially for UC treatment. In a phase II study, conducted with 194 patients with moderate to severe UC activity, higher rates of clinical response and remission were observed after 8 weeks of treatment than with placebo (71). Furthermore, there was a reduction in C-reactive protein levels and in the IBD activity marker, fecal calprotectin. However, adverse effects such as headache, abdominal pain, dizziness and infection-related events like nasopharyngitis accompanied the disease amelioration.

Finally, although biological therapies present great potential to treat IBD by blocking inflammatory cytokines or their related pathways, their use still remains controversial because of the undesirable side effects and the high treatment cost.

\section{Cellular therapy for IBD}

As stated above, current therapies for IBD include the use of drugs aimed at the modulation of inflammation and immune response. However, currently available therapies are not completely effective, many patients are refractory to them, and all are associated with a number of adverse effects. This scenario has encouraged the search for new treatments such as cellular therapy for IBD patients.

The characteristic of stem cells to self-renew and regenerate tissues, together with their immune modulatory potential, has been investigated as an alternative therapy for IBD. In this context, autologous hematopoietic stem cell transplantation (HSCT) has been used to treat IBD in both experimental and human studies, with encouraging results (Figure 1). Treatment of autoimmune or inflammatory diseases with HSCT is based on the rationale that the patient's immune system has a defect in self-tolerance, which results in direction of immune responses against cells and tissues of the body itself. Some studies of HSCT as a therapy for experimental colitis in mice showed that immunosuppressive therapy followed by cell transplantation might be an efficient approach for IBD control. In those HSCT studies, cyclophosphamide or total body irradiation were used as immunosuppressive therapy, followed by bone marrow transplantation to restore the immune compartment and, presumably, self-tolerance. In those studies, the investigators found that prompt bone marrow reconstitution after immune ablation was essential to avoid mice mortality, indicating that the therapeutic effect of HSCT was essentially due to the immunosuppression used prior to transplantation while HSC were required to avoid the receptor loss $(72,73)$. Another study demonstrated the efficacy of colonic stem cell transplantation in the control of murine colitis. IL-10/- mice that develop colitis spontaneously received local infusion of intracolonic stem cells extracted from the colon of adult C57BL/6 mice; this was found to be followed by improvement of the intestinal inflammation. In general, transplanted mice had restoration of gut histopathological features, intestinal permeability, and decreased visceral hypersensitivity. The authors suggested that this method might be safer and present fewer adverse effects than systemic administration of stem cells (74).

Regarding human studies, in 2012 the European Group for Blood and Marrow Transplantation published guidelines for the selection of patients with autoimmune diseases who meet the requirements for HSCT. Briefly, cell therapy might be indicated for patients with active disease, refractory or uncontrolled by pharmacological conventional therapies (75).

A clinical study of autologous HSCT, in 24 active $C D$ patients refractory to conventional therapy including anti-TNF treatment, was performed in Chicago. One year after transplantation, $91 \%$ of patients had not restarted CD medical therapy; however, this percentage dropped to $19 \%$ after 5 years of follow-up (76). Hasselblatt et al. (77) reported the results of $12 \mathrm{CD}$ patients who also underwent autologous transplantation of hematopoietic stem cells for IBD treatment. Of those, 5 achieved a clinical and endoscopic remission within 6 months after HSCT. However, even with the occurrence of relapse in some patients during the follow-up (average of 3 years), disease activity was controlled by low-dose corticosteroids and immunosuppressive therapy. Clinical remission was achieved 3 months after HSCT in 4 active-moderate or severe CD patients who were refractory or intolerant to multiple drugs including infliximab (78).

Owing to the immune modulatory capacity and plasticity of mesenchymal stem cells (MSC), protocols using MSC as a therapy for various diseases have been described with promising results. MSC are a heterogeneous population of fibroblast-like cells involved in various pathways and diverse biological processes. They can be isolated from bone marrow and many other adult tissues such as adipose tissues. The functions of the MSC are mainly related to their capacity to differentiate into chondrocytes, adipocytes and osteocytes (79). Most important, MSC are able to inhibit Th17 cell differentiation and function in addition to inducing a regulatory $T$ (Treg) cell phenotype (80), which is essential for the control of intestinal inflammation (Figure 1).

Experimental IBD studies showed encouraging results after MSC infusion. Accordingly, allogeneic, syngeneic, or xenogeneic MSC may act by inhibiting chemokines (81) and proinflammatory cytokines such as TNF- $\alpha(81,82)$, IL-1 $\beta$ 
(82), IL-17, IL-23, IFN- $\gamma$, and IL-6 (83) in the colon of mice with colitis. Moreover, reduction in Th1 response along with the induction of Treg cells and the cytokine IL-10 has been observed after MSC transplantation (81). Yabana et al. (84) showed that the infusion of MSC could help restore the epithelial barrier integrity and ameliorate damaged crypts caused by colitis. In addition, after MSC treatment, mice showed significant improvement in signs such as weight loss and diarrhea, normalization of colon length, and increased survival post-MSC infusion (81-83).

Topical application of MSC in the colon of rats with colitis led to accelerated healing of damaged mucosa. These effects might have been mediated by vascular endothelial growth factor (VEGF) and transforming growth factor (TGF$\beta$ ) provided by MSC in the inflamed gut (85). In addition, intraperitoneal infusion of MSC in rats with TNBS-induced colitis resulted in improvement of intestinal inflammation, reduced collagen deposition and epithelial apoptosis, with diminished levels of TNF- $\alpha$ and IL-1 $\beta$ in the colon. However, the levels of VEGF and TGF- $\beta$ were not altered after therapy (86). Recently, Chen et al. (87) also demonstrated the efficacy of MSC in the treatment of TNBS-induced colitis in BALB/c mice. The treatment effect was mediated by a decrease in Th1-Th17 cells, with subsequent reductions in inflammatory cytokines and increased Th2 response. Treatment with MSC also induced $\mathrm{CD} 4{ }^{+} \mathrm{CD} 25^{+}{ }^{+}$Foxp3 ${ }^{+}$ regulatory $T$ cells with increased levels of TGF- $\beta$, IL-10 and Foxp3 expression, able to control inflammatory or activated responses.

In human studies, injection of MSC into fistulas secondary to $C D$ resulted in closure of the lesions in most cases. Ciccocioppo et al. (88) reported that 7 of 10 patients showed complete fistula closure and 3 evolved with partial closure of the lesion. Furthermore, one clinical trial in humans with IBD assessed the efficacy of autologous bone marrow-derived MSC in 10 refractory CD patients. The characteristics of MSC isolated from CD patients were also assessed. Surprisingly, morphology, phenotype, surface marker expression, growth potential, and immune modulatory capacity of MSC derived from the CD patients were preserved. Of the 10 patients, 2 had endoscopic improvement 6 weeks after MSC infusion and 3 underwent surgery because of a worsening in health condition. A trend towards reduction of total $\mathrm{CD}^{+}{ }^{+} \mathrm{T}$ cells and augmentation of CD4 ${ }^{+}$ $\mathrm{CD}_{127^{+}}$Treg cells coupled to a reduction in inflammatory cytokines was also observed in colon biopsies. However, this study suggested that the immune modulatory effects of MSC per se may not be sufficient for disease remission and

\section{References}

1. Zhang YZ, Li YY. Inflammatory bowel disease: pathogenesis. World J Gastroenterol 2014; 20: 91-99, doi: 10.3748/wjg.v20. i1.91.

2. Kappelman MD, Moore KR, Allen JK, Cook SF. Recent trends in the prevalence of Crohn's disease and ulcerative that more trials are required to discover the effects of this cellular therapy in IBD (89).

In addition to stem cell therapy, various studies in experimental models have shown that several types of tolerogenic or regulatory dendritic cells (Reg-DCs) can also ameliorate inflammatory diseases (Figure 1). Reg-DCs express low levels of major histocompatibility complex $(\mathrm{MHC})$ and costimulatory molecules. On the other hand, fecal extracts, denoted as cecal bacterial antigen (CBA), present a major protein related to the IBD pathogenesis, carbonic anhydrase I (CA I). In a previous study, Reg-DCs were pulsed in culture with CA I (Reg-DCsCAI) and treatment of mice with Reg-DCsCAI improved colitis, probably through an antigen-specific response that directed the immune reaction to a regulatory profile (90), thus pointing to other options for IBD treatment based on cellular therapy. Overall, these results indicated that cellular therapy may be an alternative to conventional treatments in the near future as another option for patients refractory to current therapies.

\section{Concluding remarks}

In conclusion, this review summarizing different aspects of the therapeutic approaches used for IBD patients was prompted by the increasing number of $C D$ and $U C$ cases throughout the world and by questions about the effectiveness and side effects of available treatments and the quality of life of the subjects affected by these inflammatory conditions. The ideal therapy should be able to successfully control the complex scenario involved in the pathogenesis of IBD that seems to result from an interplay of environmental, immune, genetic, and microbial alterations in the gut. Nevertheless, although effective in a number of conditions, the current therapeutic options are still not totally able to control the multifaceted causes and consequences of the disease. Further studies are necessary and should be conducted in order to develop novel therapies and improve those already in use so as to achieve better outcomes of CD and UC in affected patients.

\section{Acknowledgments}

The authors would like to thank FAPESP (\#2010/ 20162-7) and CNPq (\#482390/2013-1) for financial and technical support. The research leading to these results has also received support and funding from the Núcleo de Apoio à Pesquisa em Doenças Inflamatórias (NAPDIN) under grant agreement \#11.1.21625.01.0. colitis in a commercially insured US population. Dig Dis Sci 2013; 58: 519-525, doi: 10.1007/s10620-012-2371-5.

3. Burisch J, Jess T, Martinato M, Lakatos PL. The burden of inflammatory bowel disease in Europe. J Crohns Colitis 2013; 7: 322-337, doi: 10.1016/j.crohns.2013.01.010. 
4. Ng SC, Tang W, Ching JY, Wong M, Chow CM, Hui AJ, et al. Incidence and phenotype of inflammatory bowel disease based on results from the Asia-pacific Crohn's and colitis epidemiology study. Gastroenterology 2013; 145: 158-165, doi: 10.1053/j.gastro.2013.04.007.

5. Wong $\mathrm{SH}, \mathrm{Ng} \mathrm{SC}$. What can we learn from inflammatory bowel disease in developing countries? Curr Gastroenterol Rep 2013; 15: 313, doi: 10.1007/s11894-013-0313-9.

6. Lee JC. Predicting the course of IBD: light at the end of the tunnel? Dig Dis 2012; 30 (Suppl 1): 95-99, doi: 10.1159/ 000341132.

7. Taylor KM, Irving PM. Optimization of conventional therapy in patients with IBD. Nat Rev Gastroenterol Hepatol 2011; 8: 646-656, doi: 10.1038/nrgastro.2011.172.

8. Kaiser GC, Yan F, Polk DB. Mesalamine blocks tumor necrosis factor growth inhibition and nuclear factor kappaB activation in mouse colonocytes. Gastroenterology 1999; 116 : 602-609, doi: 10.1016/S0016-5085(99)70182-4.

9. Rousseaux C, Lefebvre B, Dubuquoy L, Lefebvre P, Romano $\mathrm{O}$, Auwerx $\mathrm{J}$, et al. Intestinal antiinflammatory effect of 5aminosalicylic acid is dependent on peroxisome proliferatoractivated receptor-gamma. J Exp Med 2005; 201: 1205-1215, doi: 10.1084/jem.20041948.

10. Dubuquoy L, Rousseaux C, Thuru X, Peyrin-Biroulet L, Romano O, Chavatte P, et al. PPARgamma as a new therapeutic target in inflammatory bowel diseases. Gut 2006; 55: 1341-1349, doi: 10.1136/gut.2006.093484.

11. Tromm A, Bunganic I, Tomsova E, Tulassay Z, Lukas M, Kykal $\mathrm{J}$, et al. Budesonide $9 \mathrm{mg}$ is at least as effective as mesalamine $4.5 \mathrm{~g}$ in patients with mildly to moderately active Crohn's disease. Gastroenterology 2011; 140: 425-434, doi: 10.1053/j.gastro.2010.11.004.

12. Loftus EV Jr, Kane SV, Bjorkman D. Systematic review: short-term adverse effects of 5-aminosalicylic acid agents in the treatment of ulcerative colitis. Aliment Pharmacol Ther 2004; 19: 179-189, doi: 10.1111/j.0269-2813.2004.01827.x.

13. Rubin DT, Siegel CA, Kane SV, Binion DG, Panaccione R, Dubinsky MC, et al. Impact of ulcerative colitis from patients' and physicians' perspectives: Results from the UC: NORMAL survey. Inflamm Bowel Dis 2009; 15: 581-588, doi: 10.1002/ ibd.20793.

14. Martinez Gonzalez J, Busto Bea V, Mesonero Gismero F, Parejo Carbonell S, Garrido E, Lopez San Roman A. [Rescue therapy with sulfasalazine prior to immunosuppressive or biological agents in ulcerative colitis poorly controlled with mesalazine]. Gastroenterol Hepatol 2013; 36: 7-10, doi: 10.1016/j.gastrohep.2012.08.005.

15. Thorkildsen LT, Nwosu FC, Avershina E, Ricanek P, Perminow G, Brackmann S, et al. Dominant fecal microbiota in newly diagnosed untreated inflammatory bowel disease patients. Gastroenterol Res Pract 2013; 2013: 636785, doi: $10.1155 / 2013 / 636785$.

16. Sutherland L, Singleton J, Sessions J, Hanauer S, Krawitt E, Rankin G, et al. Double blind, placebo controlled trial of metronidazole in Crohn's disease. Gut 1991; 32: 1071-1075, doi: 10.1136/gut.32.9.1071.

17. Maeda Y, Ng SC, Durdey P, Burt C, Torkington J, Rao PK, et al. Randomized clinical trial of metronidazole ointment versus placebo in perianal Crohn's disease. Br J Surg 2010; 97: 1340-1347, doi: 10.1002/bjs.7121.

18. Ursing B, Alm T, Barany F, Bergelin I, Ganrot-Norlin K, Hoevels
$\mathrm{J}$, et al. A comparative study of metronidazole and sulfasalazine for active Crohn's disease: the cooperative Crohn's disease study in Sweden. II. Result. Gastroenterology 1982; 83: 550-562.

19. Castiglione F, Rispo A, Di Girolamo E, Cozzolino A, Manguso $\mathrm{F}$, Grassia R, et al. Antibiotic treatment of small bowel bacterial overgrowth in patients with Crohn's disease. Aliment Pharmacol Ther 2003; 18: 1107-1112, doi: 10.1046/j.13652036.2003.01800.x.

20. Thia KT, Mahadevan U, Feagan BG, Wong C, Cockeram A, Bitton $A$, et al. Ciprofloxacin or metronidazole for the treatment of perianal fistulas in patients with Crohn's disease: a randomized, double-blind, placebo-controlled pilot study. Inflamm Bowel Dis 2009; 15: 17-24, doi: 10.1002/ibd.20608.

21. Prantera C, Lochs $H$, Campieri M, Scribano ML, Sturniolo GC, Castiglione F, et al. Antibiotic treatment of Crohn's disease: results of a multicentre, double blind, randomized, placebocontrolled trial with rifaximin. Aliment Pharmacol Ther 2006; 23: 1117-1125, doi: 10.1111/j.1365-2036.2006.02879.x.

22. Rutgeerts $P$, Van Assche G, Vermeire S, D'Haens G, Baert $F$, Noman $M$, et al. Ornidazole for prophylaxis of postoperative Crohn's disease recurrence: a randomized, double-blind, placebo-controlled trial. Gastroenterology 2005; 128: 856-861, doi: 10.1053/j.gastro.2005.01.010.

23. D'Haens GR, Vermeire S, Van Assche G, Noman M, Aerden I, Van Olmen G, et al. Therapy of metronidazole with azathioprine to prevent postoperative recurrence of Crohn's disease: a controlled randomized trial. Gastroenterology 2008; 135: 1123-1129, doi: 10.1053/j.gastro.2008.07.010.

24. Petrof EO, Claud EC, Sun J, Abramova T, Guo Y, Waypa TS, et al. Bacteria-free solution derived from Lactobacillus plantarum inhibits multiple NF-kappaB pathways and inhibits proteasome function. Inflamm Bowel Dis 2009; 15: 15371547, doi: 10.1002/ibd.20930.

25. Sood A, Midha V, Makharia GK, Ahuja V, Singal D, Goswami $\mathrm{P}$, et al. The probiotic preparation, VSL\#3 induces remission in patients with mild-to-moderately active ulcerative colitis. Clin Gastroenterol Hepatol 2009; 7: 1202-9, 1209, doi: 10.1016/ j.cgh.2009.07.016.

26. Ford AC, Bernstein CN, Khan KJ, Abreu MT, Marshall JK Talley NJ, et al. Glucocorticosteroid therapy in inflammatory bowel disease: systematic review and meta-analysis. Am J Gastroenterol 2011; 106: 590-599, doi: 10.1038/ajg.2011.70.

27. Baron JH, Connell AM, Kanaghinis TG, Lennard-Jones JE, Jones AF. Out-patient treatment of ulcerative colitis. Comparison between three doses of oral prednisone. $\mathrm{Br}$ Med J 1962; 2: 441-443, doi: 10.1136/bmj.2.5302.441.

28. Rhodes JM, Robinson R, Beales I, Pugh S, Dickinson R, Dronfield M, et al. Clinical trial: oral prednisolone metasulfobenzoate (Predocol) vs. oral prednisolone for active ulcerative colitis. Aliment Pharmacol Ther 2008; 27: 228-240, doi: 10.1111/j.1365-2036.2007.03569.x.

29. Travis SP, Danese S, Kupcinskas L, Alexeeva O, D'Haens G, Gibson PR, et al. Once-daily budesonide MMX in active, mild-to-moderate ulcerative colitis: results from the randomised CORE II study. Gut 2014; 63: 433-441, doi: 10.1136/ gutjnl-2012-304258.

30. Sandborn WJ, Travis S, Moro L, Jones R, Gautille T, Bagin R, et al. Once-daily budesonide MMX $(R)$ extended-release tablets induce remission in patients with mild to moderate ulcerative colitis: results from the CORE I study. Gastroenterology 2012; 
143: 1218-1226, doi: 10.1053/j.gastro.2012.08.003.

31. Mulder CJ, Fockens $P$, Meijer JW, van der HH, Wiltink EH, Tytgat GN. Beclomethasone dipropionate $(3 \mathrm{mg}$ ) versus 5aminosalicylic acid $(2 \mathrm{~g})$ versus the combination of both $(3 \mathrm{mg} / 2 \mathrm{~g}$ ) as retention enemas in active ulcerative proctitis. Eur J Gastroenterol Hepatol 1996; 8: 549-553, doi: 10.1097/ 00042737-199606000-00010.

32. Hartmann F, Stein J. Clinical trial: controlled, open, randomized multicentre study comparing the effects of treatment on quality of life, safety and efficacy of budesonide or mesalazine enemas in active left-sided ulcerative colitis. Aliment Pharmacol Ther 2010; 32: 368-376, doi: 10.1111/j.1365-2036. 2010.04354.x.

33. Markowitz J, Grancher K, Kohn N, Lesser M, Daum F. A multicenter trial of 6-mercaptopurine and prednisone in children with newly diagnosed Crohn's disease. Gastroenterology 2000; 119: 895-902, doi: 10.1053/gast.2000.18144

34. Wine E, Mack DR, Hyams J, Otley AR, Markowitz J, Crandall $\mathrm{WV}$, et al. Interleukin- 6 is associated with steroid resistance and reflects disease activity in severe pediatric ulcerative colitis. J Crohns Colitis 2013; 7: 916-922, doi: 10.1016/j.crohns. 2012.12.012.

35. De ludicibus S, Stocco G, Martelossi S, Londero M, Ebner E, Pontillo A, et al. Genetic predictors of glucocorticoid response in pediatric patients with inflammatory bowel diseases. J Clin Gastroenterol 2011; 45: e1-e7, doi: 10.1097/MCG.0b013e 3181 e8ae93.

36. Ardizzone S, Maconi G, Russo A, Imbesi V, Colombo E, Bianchi PG. Randomised controlled trial of azathioprine and 5aminosalicylic acid for treatment of steroid dependent ulcerative colitis. Gut 2006; 55: 47-53, doi: 10.1136/gut.2005.068809.

37. Reinisch W, Angelberger S, Petritsch W, Shonova O, Lukas $\mathrm{M}$, Bar-Meir S, et al. Azathioprine versus mesalazine for prevention of postoperative clinical recurrence in patients with Crohn's disease with endoscopic recurrence: efficacy and safety results of a randomised, double-blind, double-dummy, multicentre trial. Gut 2010; 59: 752-759, doi: 10.1136/gut. 2009.194159.

38. Thomas CW, Myhre GM, Tschumper R, Sreekumar R, Jelinek D, McKean DJ, et al. Selective inhibition of inflammatory gene expression in activated T lymphocytes: a mechanism of immune suppression by thiopurines. J Pharmacol Exp Ther 2005; 312: 537-545, doi: 10.1124/jpet.104.074815.

39. Punati J, Markowitz J, Lerer T, Hyams J, Kugathasan S, Griffiths A, et al. Effect of early immunomodulator use in moderate to severe pediatric Crohn disease. Inflamm Bowel Dis 2008; 14: 949-954, doi: 10.1002/ibd.20412.

40. Gisbert JP, Nino P, Cara C, Rodrigo L. Comparative effectiveness of azathioprine in Crohn's disease and ulcerative colitis: prospective, long-term, follow-up study of 394 patients. Aliment Pharmacol Ther 2008; 28: 228-238, doi: 10.1111/j.1365-2036.2008.03732.x

41. Hindorf $U$, Johansson M, Eriksson A, Kvifors E, Almer SH Mercaptopurine treatment should be considered in azathioprine intolerant patients with inflammatory bowel disease. Aliment Pharmacol Ther 2009; 29: 654-661, doi: 10.1111/j. 1365-2036.2008.03925.x.

42. Suares NC, Hamlin PJ, Greer DP, Warren L, Clark T, Ford AC. Efficacy and tolerability of methotrexate therapy for refractory Crohn's disease: a large single-centre experience. Aliment Pharmacol Ther 2012; 35: 284-291, doi: 10.1111/ j.1365-2036.2011.04925.x.

43. Oren R, Arber N, Odes S, Moshkowitz M, Keter D, Pomeranz I, et al. Methotrexate in chronic active ulcerative colitis: a double-blind, randomized, Israeli multicenter trial. Gastroenterology 1996; 110: 1416-1421, doi: 10.1053/gast. 1996.v110.pm8613046.

44. Cummings JR, Herrlinger KR, Travis SP, Gorard DA Mclntyre AS, Jewell DP. Oral methotrexate in ulcerative colitis. Aliment Pharmacol Ther 2005; 21: 385-389, doi: 10.1111/j.1365-2036.2005.02331.x.

45. Nathan DM, Iser JH, Gibson PR. A single center experience of methotrexate in the treatment of Crohn's disease and ulcerative colitis: a case for subcutaneous administration J Gastroenterol Hepatol 2008; 23: 954-958, doi: 10.1111/ j.1440-1746.2007.05006.x.

46. Cronstein BN, Naime D, Ostad E. The antiinflammatory mechanism of methotrexate. Increased adenosine release at inflamed sites diminishes leukocyte accumulation in an in vivo model of inflammation. J Clin Invest 1993; 92: 26752682, doi: 10.1172/JCl116884.

47. Valentino PL, Church PC, Shah PS, Beyene J, Griffiths AM, Feldman BM, et al. Hepatotoxicity caused by methotrexate therapy in children with inflammatory bowel disease: a systematic review and meta-analysis. Inflamm Bowel Dis 2014; 20: 47-59, doi: 10.1097/01.MIB.0000436953.88522.3e.

48. Valatas $V$, Vakas M, Kolios $G$. The value of experimental models of colitis in predicting efficacy of biological therapies for inflammatory bowel diseases. Am J Physiol Gastrointest Liver Physiol 2013; 305: G763-G785, doi: 10.1152/ajpgi. 00004.2013

49. Garces S, Demengeot J, Benito-Garcia E. The immunogenicity of anti-TNF therapy in immune-mediated inflammatory diseases: a systematic review of the literature with a metaanalysis. Ann Rheum Dis 2013; 72: 1947-1955, doi: 10.1136/ annrheumdis-2012-202220.

50. Mowat C, Cole A, Windsor A, Ahmad T, Arnott I, Driscoll R, et al. Guidelines for the management of inflammatory bowel disease in adults. Gut 2011; 60: 571-607, doi: 10.1136/gut. 2010.224154.

51. Targan SR, Hanauer SB, van Deventer SJ, Mayer L, Present $\mathrm{DH}$, Braakman $\mathrm{T}$, et al. A short-term study of chimeric monoclonal antibody cA2 to tumor necrosis factor alpha for Crohn's disease. Crohn's Disease cA2 Study Group. N Engl J Med 1997; 337: 1029-1035, doi: 10.1056/NEJM19971009337 1502.

52. Dignass A, Van Assche G, Lindsay JO, Lemann M, Soderholm J, Colombel JF, et al. The second European evidence-based Consensus on the diagnosis and management of Crohn's disease: Current management. J Crohns Colitis 2010; 4: 28-62, doi: 10.1016/j.crohns.2009.12.002.

53. Rutgeerts $P$, Van Assche G, Vermeire S. Review article: Infliximab therapy for inflammatory bowel disease -7 years on. Aliment Pharmacol Ther 2006; 23: 451-463, doi: 10.1111/ j.1365-2036.2006.02786.x.

54. Molnar T, Farkas K, Nyari T, Szepes Z, Nagy F, Wittmann T. Frequency and predictors of loss of response to infliximab or adalimumab in Crohn's disease after one-year treatment period - a single center experience. J Gastrointestin Liver Dis 2012; 21: 265-269.

55. Steenholdt C, Al-Khalaf M, Brynskov J, Bendtzen K, Thomsen OO, Ainsworth MA. Clinical implications of variations in 
anti-infliximab antibody levels in patients with inflammatory bowel disease. Inflamm Bowel Dis 2012; 18: 2209-2217, doi: 10.1002/ibd.22910.

56. Lee LY, Sanderson JD, Irving PM. Anti-infliximab antibodies in inflammatory bowel disease: prevalence, infusion reactions, immunosuppression and response, a meta-analysis. Eur J Gastroenterol Hepatol 2012; 24: 1078-1085, doi: 10.1097/MEG.0b013e32835558cf.

57. Colombel JF, Rutgeerts PJ, Sandborn WJ, Yang M, Camez A, Pollack PF, et al. Adalimumab induces deep remission in patients with Crohn's disease. Clin Gastroenterol Hepatol 2014; 12: 414-422, doi: 10.1016/j.cgh.2013.06.019.

58. Feagan BG, Coteur G, Tan S, Keininger DL, Schreiber S. Clinically meaningful improvement in health-related quality of life in a randomized controlled trial of certolizumab pegol maintenance therapy for Crohn's disease. Am J Gastroenterol 2009; 104: 1976-1983, doi: 10.1038/ajg.2009.199.

59. Sandborn WJ, Feagan BG, Marano C, Zhang H, Strauss R, Johanns J, et al. Subcutaneous golimumab induces clinical response and remission in patients with moderate-to-severe ulcerative colitis. Gastroenterology 2014; 146: 85-95, doi: 10.1053/j.gastro.2013.05.048.

60. Nesbitt A, Fossati G, Bergin M, Stephens P, Stephens S, Foulkes $\mathrm{R}$, et al. Mechanism of action of certolizumab pegol (CDP870): in vitro comparison with other anti-tumor necrosis factor alpha agents. Inflamm Bowel Dis 2007; 13: 1323-1332, doi: 10.1002/ibd.20225.

61. Hoentjen F, van Bodegraven AA. Safety of anti-tumor necrosis factor therapy in inflammatory bowel disease. World J Gastroenterol 2009; 15: 2067-2073, doi: 10.3748/ wjg.15.2067.

62. Schnitzler F, Fidder $\mathrm{H}$, Ferrante $\mathrm{M}$, Ballet $\mathrm{V}$, Noman $\mathrm{M}$, Van Assche $G$, et al. Outcome of pregnancy in women with inflammatory bowel disease treated with antitumor necrosis factor therapy. Inflamm Bowel Dis 2011; 17: 1846-1854, doi: 10.1002/ibd.21583.

63. Mahadevan U, Wolf DC, Dubinsky M, Cortot A, Lee SD, Siegel CA, et al. Placental transfer of anti-tumor necrosis factor agents in pregnant patients with inflammatory bowel disease. Clin Gastroenterol Hepatol 2013; 11: 286-292, doi: 10.1016/j.cgh.2012.11.011.

64. Neurath MF, Fuss I, Kelsall BL, Stuber E, Strober W. Antibodies to interleukin 12 abrogate established experimental colitis in mice. J Exp Med 1995; 182: 1281-1290, doi: 10.1084/jem.182.5.1281.

65. Hue S, Ahern P, Buonocore S, Kullberg MC, Cua DJ, McKenzie BS, et al. Interleukin-23 drives innate and T cellmediated intestinal inflammation. J Exp Med 2006; 203: 2473-2483, doi: 10.1084/jem.20061099.

66. Benson JM, Peritt D, Scallon BJ, Heavner GA, Shealy DJ, Giles-Komar JM, et al. Discovery and mechanism of ustekinumab: a human monoclonal antibody targeting interleukin-12 and interleukin-23 for treatment of immune-mediated disorders. MAbs 2011; 3: 535-545, doi: 10.4161/mabs.3.6. 17815.

67. Sandborn WJ, Gasink C, Gao LL, Blank MA, Johanns J, Guzzo C, et al. Ustekinumab induction and maintenance therapy in refractory Crohn's disease. N Engl J Med 2012; 367: 1519-1528, doi: 10.1056/NEJMoa1203572.

68. Leger OJ, Yednock TA, Tanner L, Horner HC, Hines DK, Keen $S$, et al. Humanization of a mouse antibody against human alpha-4 integrin: a potential therapeutic for the treatment of multiple sclerosis. Hum Antibodies 1997; 8: 316.

69. Juillerat $\mathrm{P}$, Wasan $\mathrm{SK}$, Fowler SA, Friedman S, Pabby VK, Coukas JA, et al. Efficacy and safety of natalizumab in Crohn's disease patients treated at 6 Boston academic hospitals Inflamm Bowel Dis 2013; 19: 2457-2463, doi: 10.1097/MIB. Ob013e3182a32a0d.

70. Flanagan ME, Blumenkopf TA, Brissette WH, Brown MF, Casavant JM, Shang-Poa C, et al. Discovery of CP-690,550: a potent and selective Janus kinase (JAK) inhibitor for the treatment of autoimmune diseases and organ transplant rejection. J Med Chem 2010; 53: 8468-8484, doi: 10.1021/ jm1004286.

71. Sandborn WJ, Ghosh S, Panes J, Vranic I, Su C, Rousell S, et al. Tofacitinib, an oral Janus kinase inhibitor, in active ulcerative colitis. N Engl J Med 2012; 367: 616-624, doi 10.1056/NEJMoa1112168.

72. Godoi DF, Cardoso CR, Ferraz DB, Provinciatto PR, Cunha FQ, Silva JS, et al. Hematopoietic SCT modulates gut inflammation in experimental inflammatory bowel disease. Bone Marrow Transplant 2010; 45: 1562-1571, doi: 10.1038/ bmt.2010.6.

73. Godoi DF, Cardoso CR, Silva MJ, Ferraz DB, Provinciatto $P R$, Cunha $F Q$, et al. Reappraisal of total body irradiation followed by bone marrow transplantation as a therapy for inflammatory bowel disease. Immunobiology 2013; 218: 317324, doi: 10.1016/j.imbio.2012.05.012.

74. Zhou Q, Price DD, Dreher KL, Pronold B, Callam CS, Sharma $\mathrm{J}$, et al. Localized colonic stem cell transplantation enhances tissue regeneration in murine colitis. J Cell Mol Med 2012; 16 1900-1915, doi: 10.1111/j.1582-4934.2011.01485.x.

75. Snowden JA, Saccardi R, Allez M, Ardizzone S, Arnold R, Cervera R, et al. Haematopoietic SCT in severe autoimmune diseases: updated guidelines of the European Group for Blood and Marrow Transplantation. Bone Marrow Transplant 2012; 47: 770-790, doi: 10.1038/bmt.2011.185.

76. Burt RK, Craig RM, Milanetti F, Quigley K, Gozdziak P Bucha J, et al. Autologous nonmyeloablative hematopoietic stem cell transplantation in patients with severe anti-TNF refractory Crohn disease: long-term follow-up. Blood 2010 116: 6123-6132, doi: 10.1182/blood-2010-06-292391.

77. Hasselblatt P, Drognitz K, Potthoff K, Bertz H, Kruis W, Schmidt C, et al. Remission of refractory Crohn's disease by high-dose cyclophosphamide and autologous peripheral blood stem cell transplantation. Aliment Pharmacol Ther 2012; 36: 725-735, doi: 10.1111/apt.12032.

78. Cassinotti A, Annaloro C, Ardizzone S, Onida F, Della Volpe $A$, Clerici $M$, et al. Autologous haematopoietic stem cell transplantation without CD34 + cell selection in refractory Crohn's disease. Gut 2008; 57: 211-217, doi: 10.1136/gut. 2007.128694.

79. Uccelli A, Moretta L, Pistoia V. Mesenchymal stem cells in health and disease. Nat Rev Immunol 2008; 8: 726-736, doi: 10.1038/nri2395.

80. Ghannam S, Pene J, Moquet-Torcy G, Jorgensen C, Yssel H. Mesenchymal stem cells inhibit human Th17 cell differentiation and function and induce a $T$ regulatory cell phenotype. J Immunol 2010; 185: 302-312, doi: 10.4049/jimmunol. 0902007.

81. Gonzalez MA, Gonzalez-Rey E, Rico L, Buscher D, Delgado 
M. Adipose-derived mesenchymal stem cells alleviate experimental colitis by inhibiting inflammatory and autoimmune responses. Gastroenterology 2009; 136: 978-989, doi: 10.1053/j.gastro.2008.11.041.

82. He XW, He XS, Lian L, Wu XJ, Lan P. Systemic infusion of bone marrow-derived mesenchymal stem cells for treatment of experimental colitis in mice. Dig Dis Sci 2012; 57: 31363144, doi: 10.1007/s10620-012-2290-5.

83. Liang L, Dong C, Chen X, Fang Z, Xu J, Liu M, et al. Human umbilical cord mesenchymal stem cells ameliorate mice trinitrobenzene sulfonic acid (TNBS)-induced colitis. Cell Transplant 2011; 20: 1395-1408, doi: 10.3727/096368910X 557245.

84. Yabana T, Arimura $\mathrm{Y}$, Tanaka H, Goto A, Hosokawa M, Nagaishi K, et al. Enhancing epithelial engraftment of rat mesenchymal stem cells restores epithelial barrier integrity. J Pathol 2009; 218: 350-359, doi: 10.1002/path.2535.

85. Hayashi $Y$, Tsuji S, Tsujii M, Nishida T, Ishii S, lijima $H$, et al. Topical implantation of mesenchymal stem cells has beneficial effects on healing of experimental colitis in rats. J Pharmacol Exp Ther 2008; 326: 523-531, doi: 10.1124/jpet.108.137083.

86. Castelo-Branco MT, Soares ID, Lopes DV, Buongusto F, Martinusso CA, do Rosario A Jr, et al. Intraperitoneal but not intravenous cryopreserved mesenchymal stromal cells home to the inflamed colon and ameliorate experimental colitis. PLoS One 2012; 7: e33360, doi: 10.1371/journal.pone.0033360.

87. Chen $Q Q$, Yan L, Wang CZ, Wang WH, Shi H, Su BB, et al. Mesenchymal stem cells alleviate TNBS-induced colitis by modulating inflammatory and autoimmune responses. World J Gastroenterol 2013; 19: 4702-4717, doi: 10.3748/wjg.v19. i29.4702.

88. Ciccocioppo R, Bernardo ME, Sgarella A, Maccario R, Avanzini MA, Ubezio $\mathrm{C}$, et al. Autologous bone marrowderived mesenchymal stromal cells in the treatment of fistulising Crohn's disease. Gut 2011; 60: 788-798, doi: 10.1136/gut.2010.214841.

89. Duijvestein M, Vos AC, Roelofs $H$, Wildenberg ME, Wendrich $\mathrm{BB}$, Verspaget HW, et al. Autologous bone marrow-derived mesenchymal stromal cell treatment for refractory luminal Crohn's disease: results of a phase I study. Gut 2010; 59: 1662-1669, doi: 10.1136/gut.2010.215152.

90. Yamanishi H, Murakami H, Ikeda Y, Abe M, Kumagi T, Hiasa $Y$, et al. Regulatory dendritic cells pulsed with carbonic anhydrase I protect mice from colitis induced by CD4 + . J Immunol 2012; 188: 2164-2172, doi: 10.4049/jimmunol. 1100559. 